\title{
A DISPUTA CULTURAL: O PENSAMENTO CONSERVADOR NO ENSINO MÉDIO BRASILEIRO1
}

\section{THE CULTURAL DISPUTE: CONSERVATIVE THINKING IN BRAZILIAN HIGH SCHOOL}

\author{
Dirce Zan ${ }^{2}$ \\ Universidade Estadual de Londrina Campinas - UNICAMP \\ Nora Krawczyk ${ }^{3}$ \\ Universidade Estadual de Campinas - UNICAMP
}

\begin{abstract}
Resumo
O artigo analisa como o avanço do pensamento conservador no Brasil expressa-se na disputa pela escola pública e seu consequente desmonte a partir do golpe de 2016. O conservadorismo, que tem conquistado cada vez mais poder, revela-se em iniciativas tais como a reforma do Ensino Médio, a Base Nacional Comum Curricular (BNCC), as Diretrizes Curriculares Nacionais para o Ensino Médio, o projeto Escola Sem Partido, entre outros. Para as autoras, trata-se de situação que afronta o caráter democrático da escola pública, desvaloriza a ciência, desrespeita a juventude e os trabalhadores da educação. Elas consideram ainda que as mudanças na área de educação estão em sintonia com o atual processo político regressivo e com suas demais reformas, especialmente no âmbito do trabalho e da seguridade social.
\end{abstract}

Palavras-chave: Pensamento conservador em educação; Reforma de Ensino Médio; Escola Sem Partido; Escola pública.

\section{Abstract}

The article analyzes how the advance of conservative thinking in Brazil is expressed in the dispute for the public school and its consequent dismantling since the 2016 coup. Conservatism, which has

1 Uma versão deste artigo foi publicada no livro "O Golpe de 2016 e a Educação no Brasil, 2018".

2 Possui graduação em Pedagogia (1991), mestrado (1996) e doutorado (2005) em Educação pela Universidade Estadual de Campinas. Atualmente é docente do Departamento de Ensino e Práticas Culturais (DEPRAC) e Diretora da Faculdade de Educação (2016-2020) da mesma Universidade. E presidente do FORUMDIR (Fórum Nacional de Diretores de Faculdades, Centros de Educação ou Equivalentes das Universidades Públicas Brasileiras).

${ }^{3}$ Possui graduação em Ciências da Educação (1980), Mestrado em Estado, Educação e sociedade pela Facultad Latinoamericana em Ciencias Sociales (1987), Doutorado em Educação pela Universidade Estadual de Campinas (1992) e Pós-doutorado pela Maryland University (EUA) (2016). Atualmente é professor doutor da Universidade Estadual de Campinas da Faculdade de Educação - Unicamp e membro do Grupo de Pesquisa em Política Educacional, Educação e Sociedade - GPPES. Atualmente é representante da Pós-graduação em Educação/Unicamp na Rede Latino-americana de Metodologia em Ciências Sociais. 
been gaining more and more power, reveals itself in initiatives such as High School reform, the National Common Curriculum Base (BNCC), the National Curriculum Guidelines for High School, the School Without Party project, among others. For the authors, it is a situation that afflicts the democratic character of the public school, devalues science, disrespects youth and education workers. They also consider that changes in education are in line with the current regressive political process and its other reforms, especially in the area of work and social security.

Keywords: Conservative thinking in education; High School Reform; School Without Party; Public school.

\section{INTRODUÇÃO}

As mudanças que, após o golpe de 2016, começa a sofrer a educação brasileira não estão alheias a um processo político regressivo e a reformas no âmbito das relações de trabalho e de seguridade social. Sem esse cenário teria sido impossível que a educação no Brasil tivesse chegado à situação na qual estamos atualmente. Uma situação que afronta o caráter democrático da escola pública desvaloriza a ciência, desrespeita a juventude e os trabalhadores da educação.

Na reforma do Ensino Médio, que foi apresentada em 2016 como medida provisória pelo governo Temer e ficou legitimada na Lei $\mathrm{n}^{0} 13.415^{4}$, é possível identificar o processo regressivo que a educação brasileira está vivendo e sua conformidade com outras formas de negação do conhecimento à juventude e aos professores.

O Ensino Médio brasileiro é o elo mais frágil da Educação Básica e, portanto, particularmente sensível a momentos de crises políticas. A sua identidade está em constante debate assim como o caráter que deve assumir sua expansão. A dificuldade de acordar socialmente uma expansão democrática e universalista do Ensino Médio esteve e continua no centro dos conflitos e tensões quando se tomam decisões sobre ele. Surge para a formação das elites brasileiras, expande-se por meio da conformação de um sistema dual, que destina ao filho do trabalhador a formação profissional, sem chance de continuar estudante e, quando se desmonta essa estrutura do sistema educativo fortemente segregacionista, novos setores sociais começam a aceder ao Ensino Médio. Assim a classe média abandona a escola pública. Possui uma infraestrutura precária e uma forte desvalorização docente.

As políticas governamentais, num sistema democrático, resultam em geral de embates e negociações que envolvem diferentes interesses, desencadeando disputas entre forças e projetos, às vezes até antagônicos no atinente aos rumos a serem propostos, 
neste caso, à educação. Porém, durante o governo Temer, aproveitou-se o clima autoritário que imperou no Executivo e no Legislativo e tomaram-se decisões que, anteriormente, sofreram forte oposição de vários movimentos sociais e foi objeto de intensos debates no Congresso, sem encontrar consenso.

Neste momento, estamos frente a uma reforma do Ensino Médio que, sob o manto da palavra de ordem flexibilização, está enfraquecendo o espaço público enquanto espaço educativo e degradando a condição docente.

Em especial no que diz respeito ao projeto das escolas e ao currículo, o tema da flexibilização historicamente se vincula às propostas pedagógicas alternativas. No entanto, ele ganha outra conotação quando associado a um contexto de austeridade econômica e de avanço de pensamento conservador, como o que estamos vivendo. Nesse contexto, a flexibilização passa a ser utilizada com a intenção de baratear o ensino (um professor para várias disciplinas de uma mesma área, por exemplo) e restringir projetos formativos a processos de treinamento e instrumentalização técnica.

Entretanto, o uso do termo flexibilização em propostas educacionais contribui para a sedução dos diferentes sujeitos, em especial nesse caso dos jovens estudantes do Ensino Médio, pois costuma remeter, na fantasia das pessoas, à autonomia, à livre escolha, ao espaço de criatividade e inovação. É paradigmático o fato de que a reforma de Ensino Médio estabelece uma situação totalmente oposta. Estamos frente a uma reforma que, em nome da flexibilização, exacerba os processos de exclusão e desigualdade social por meio da desregulamentação, da segregação e da precarização do ensino e do trabalho docente (KRAWCZYK \& FERETTI, 2017).

Desde os documentos curriculares dos anos de 1990 que se busca a reorganização da matriz curricular do Ensino Médio com a aglutinação em áreas das disciplinas tradicionais do currículo. No mesmo sentido de flexibilizar a organização curricular, apresentam ainda a possibilidade da oferta de um total de $25 \%$ da carga horária dos cursos de forma diversificada, segundo as culturas e características locais ou das escolas.

$\mathrm{Na}$ reforma educativa atual estabelece-se uma nova proposta de organização curricular composta por duas partes não necessariamente subsequentes e que, em nome da flexibilização, fragmenta o ensino: uma delas destinadas à formação geral do estudante (núcleo comum), com um teto de até 1.800 hs, e uma outra diversificada em 5 itinerários formativos.

O núcleo comum é definido pela Base Nacional Comum Curricular (BNCC), mas que no seu texto referenda algumas diretrizes anunciadas na Lei. Por exemplo, a 
obrigatoriedade do ensino de Matemática, Português e Inglês, além da "liberdade" de os estados definirem o restante do currículo comum.

No momento em que finalizamos esse artigo, foi homologada pelo atual ministro uma resolução da Câmara da Educação Básica do Conselho Nacional de Educação que atualiza as Diretrizes Curriculares Nacionais para o Ensino Médio ${ }^{5}$. Nesse documento, ainda sob revisão, há maiores detalhamentos sobre a oferta dos itinerários formativos, especialmente no que diz respeito à formação técnica e profissional.

Sobre esse tema, salta aos olhos a diversidade na possibilidade de oferta de tal formação. Os arranjos são os mais variados possíveis, o que nos alerta para o perigo em que podem se encontrar a rede recentemente ampliada pelo país dos Institutos Técnicos Federais $^{6}$ e a tradicional rede dos Centros Paula Souza em São Paulo ${ }^{7}$, reconhecidas instituições que contribuem para formação técnica e profissional de qualidade.

A resolução detalha também os outros itinerários formativos e remete à necessária consonância entre o currículo do Ensino Médio e o documento da BNCC que ainda não foi aprovado pelo CNE.

Outro ponto do texto sobre a Reforma do Ensino Médio que merece destaque diz respeito à abertura para a oferta desse nível de ensino por meio da Educação a Distância. Junto à homologação da alteração das DCNEM, o CNE também aprovou que até $20 \%$ da carga horária do Ensino Médio diurno, até 30\% no noturno e até $80 \%$ na modalidade de Educação de Jovens e Adultos podem ser ofertadas em EAD. A regulação e o "controle" dessa oferta serão feitos por cada estado, segundo o MEC.

A forte redução do tempo e conteúdos de formação geral e a flexibilização na forma de oferta desse nível de ensino explicitam claramente o sentido instrumental da formação pretendida e a preocupação com a melhoria dos indicadores do Brasil nos testes internacionais. Além disso, deixa cada vez mais clara a intenção de promover uma

\footnotetext{
${ }^{5}$ http://agenciabrasil.ebc.com.br/educacao/noticia/2018-11/estados-poderao-decidir-se-darao-aulasdistancia-no-ensino-medio

${ }^{6}$ Isso foi parte de um projeto de desenvolvimento tecnológico, econômico e social a expansão da Rede Federal de EPT (Educação Profissional e Tecnológica) teve início por meio da Lei oㅜ 11.195, de 18 de novembro de 2005. A primeira fase da expansão previa a construção de 64 novas unidades com objetivo de ampliar a rede federal em todo território nacional, em especial, nas periferias de grandes centros urbanos e em municípios do interior do país (MEC/SETEC, 2011). A segunda fase foi lançada em 2007 com objetivo de criar mais 150 novas unidades. Ao fim da segunda fase, em 2010, eram 214 novas unidades (SANTOS e ZAN, 2018).

7 Segundo noticiado no Jornal O Estado de São Paulo em novembro de 2017 (Disponível em educacao.estadao.com.br/noticias/geral,sao-paulo-vai-testar-escolas-tecnicas-inspiradas-na-reforma-doensino-medio. Acessado em 26/11/2018).
} 
aproximação com o setor privado para a viabilização da oferta desse nível de ensino, tornando mais atrativa para as empresas educacionais essa atuação.

A redução do tempo e do conteúdo da formação comum a todos não é uma demanda dos jovens, tal como se intenta convencer pela mídia. Isto está demonstrado nas mobilizações juvenis que buscam, sobretudo, serem autônomos e críticos, possuir os conhecimentos científicos e culturais.

A reforma educativa do Ensino Médio, porém, está inserida num movimento mais amplo de forte enfrentamento ao caráter cultural e científico da escola pública. A escola está vivendo situações que remontam há quase 100 anos e que estão sendo lideradas pelo movimento Escola Sem Partido.

O avanço do pensamento conservador na disputa pela escola não é algo genuinamente nacional e retoma batalhas que imaginávamos já superadas.

Nos anos de 1920, um professor foi processado criminalmente no sul dos Estados Unidos porque estava ensinando a teoria da evolução das espécies de Darwin a seus alunos. Segundo seus acusadores, isso contrariava a bíblia segundo o qual o homem e a mulher haviam sido criados por Deus há cinco ou seis mil anos a partir de um boneco de barro ${ }^{8}$.

Apple (2003) tem acompanhado o avanço do pensamento conservador nos EUA dominando e influenciando a sociedade em geral e a política e prática educacionais, em particular. Para ele, o país está enfrentando um amplo movimento de "modernização conservadora" que recomenda "libertar" as escolas, incluindo-as em um mercado competitivo. Restaurar a cultura tradicional comum e enfatizar a disciplina e o caráter, voltando-se para a doutrina cristã nas salas de aula, como guia de toda conduta dentro e fora da escola, são ideias que retornam. Ao mesmo tempo, o movimento defende a intensificação e o controle dos professores por meio de critérios de avaliação e testes mais rigorosos e exigentes.

Algo similar temos vivido aqui no Brasil desde o Golpe de 2016 e que se intensifica com a eleição de Jair Bolsonaro que, de certo modo, deu novo fôlego à tramitação do Projeto Escola Sem Partido nas diferentes casas legislativas. Professores são denunciados porque ensinam educação sexual nas aulas de Biologia, ou marxismo nas aulas de Filosofia. Escolas são denunciadas porque utilizam livros que retratam aspectos da cultura africana ou por discorrer sobre diversidade. Esses são só alguns dos exemplos que

\footnotetext{
${ }^{8}$ Em 1960 foi lançado o filme "O vento será tua herança", dirigido por Stanley Kramer, que retrata essa história e era também uma crítica ao macarthismo norte-americano dos anos 50.
} 
cotidianamente estão acontecendo em nossas escolas. Também está colocada a pressão para que as escolas ensinem algo que tem sido chamado de "criacionismo", ou seja, retornar ao ensinamento bíblico sobre Adão e Eva, juntamente com a evolução das espécies, apresentando-as como duas hipóteses (científicas) de surgimento da humanidade. Isto é, equiparar a religião à ciência e, em muitos casos, proibindo o ensino da Ciência nas escolas. Por exemplo, se formos para o campo das ciências humanas, como no caso da História, vamos encontrar quem defenda a negação dos 21 anos de Ditadura Militar no Brasil, a negação da importância de Paulo Freire para a educação popular no País, entre outros.

Com o ataque às ciências humanas - seja por via da exclusão da carga horária e das disciplinas obrigatórias e da carga horária para formação geral, seja pela exclusão do currículo de Filosofia e Sociologia, seja pelas denúncias do suposto viés ideológico das escolas -, pretende-se tirar da escola seu sentido democrático e crítico. É a negação do papel educativo da escola de transcender o espaço privado da família e de formação da cidadania. Lembremos que a escola pública estatal é uma construção histórica da Idade Moderna junto ao processo de secularização da educação (LUZURIAGA, 1959).

Todas essas estratégias se aproximam do que é relatado por Apple (2003) sobre a atuação da direita, isto é, são ações que têm como principal intenção mudar nosso senso comum, alterando o significado das categorias mais básicas que empregamos para compreender o mundo social e educacional e o nosso lugar nele, o que se relaciona diretamente à política de identidade. A direita tem se concentrado em alterar radicalmente aquilo que pensamos ser e como nossas principais instituições devem responder a essa alteração de identidade.

A crise do neoliberalismo no século XXI serviu como uma luva para difundir e fortalecer o movimento conservador pelo mundo. De certo modo, é possível afirmar que a disputa por agendas econômicas atuais se constrói por meio de uma guerra que é fundamentalmente discursiva e cultural e, portanto, a escola e a ciência são alvos privilegiados nesse momento.

Voltemos à reforma do Ensino Médio e a sua proposta de organização curricular em várias opções formativas.

A reforma curricular, concebida na Lei n. 13.415 de 16/02/2017, é uma nova forma de distribuição do conhecimento socialmente produzido, colocando o Ensino Médio a serviço da produção de sujeitos técnica e subjetivamente preparados do ponto de vista instrumental, tendo em vista os interesses do capital. Daí a pouca atenção voltada à 
formação de sentido amplo e crítico ou sua secundarização, assim como a exclusão, como obrigatórias, de disciplinas como Filosofia e Sociologia. Da mesma forma, é importante ressaltar o silêncio em relação às artes na formação desses estudantes.

Ao mesmo tempo, amplia-se a penetração de ideias e ideais neoliberais na formação dos estudantes. Temas como o do empreendedorismo passam a se fazer presentes nos diferentes documentos e projetos formativos. Na resolução que altera as DCNEM homologadas nesse ano de 2018, o empreendedorismo aparece como um dos eixos estruturantes da formação nos cinco itinerários formativos. Nesse documento, o empreendedorismo é assim apresentado: supõe a mobilização de conhecimentos de diferentes áreas para a formação de organizações com variadas missões voltadas ao desenvolvimento de produtos ou prestação de serviços inovadores com o uso das tecnologias (artigo 12, parágrafo $2^{\circ}$, inciso IV).

É o discurso e a lógica do mercado fortalecendo-se na formação dos estudantes do Ensino Médio. Onde anteriormente se compreendia como eixo estruturante o trabalho coletivo, a solidariedade e o compromisso social na formação dos estudantes agora se coloca como parte inerente de toda e qualquer formação princípios como o do empreendedorismo e da inovação, fortemente vinculados à perspectiva do mercado produtivo.

Mas essas mudanças não estão acontecendo sem contradições. Existem disputas e conflitos também nesse campo conservador. Por exemplo, a mesma resolução apresenta, na sessão referente à estrutura curricular, maiores detalhamentos sobre a parte comum do currículo do Ensino Médio em que se expressa a organização em quatro áreas: linguagens e suas tecnologias, matemática e suas tecnologias, ciências da natureza e suas tecnologias e ciências humanas e sociais aplicadas. No inciso IV, parágrafo $4^{\circ}$, explicita que deverão ser contemplados "estudos e práticas" de arte, especialmente em suas expressões regionais; conhecimento do mundo físico e natural e da realidade social e política, especialmente no Brasil; história do Brasil, considerando a contribuição das diferentes culturas e etnias, especialmente das matrizes indígena, africana e europeia e história e cultura afro-brasileira e indígena.

É também nas políticas voltadas para a formação de professores que podemos observar o avanço do pensamento conservador e da disputa entre projetos educacionais. Há o avanço na oferta de cursos de formação de professores por meio das instituições privadas e, principalmente, na modalidade de Educação a Distância. Ao mesmo tempo, há uma tentativa de forte interferência no currículo dos cursos de formação de professores das 
Universidades Públicas reconhecidamente instituições responsáveis por oferta de ensino de qualidade.

Recentemente no estado de São Paulo, o Conselho Estadual de Educação (CEE), por meio de deliberações, visa implementar uma concepção bastante instrumental da formação desse profissional nos currículos das instituições públicas de ensino. Sob o argumento de que os estudantes da educação básica possuem um baixo desempenho nos exames em larga escala e que esse fato resulta da má formação dos professores, o CEE propõe uma verdadeira intervenção nos cursos das universidades públicas paulistas. As deliberações do CEE sobre o tema apresentam um forte caráter de interferência curricular, no conteúdo a ser ministrado, nos tempos específicos, no superdimensionamento da responsabilidade das universidades estaduais com a formação desse profissional.

O tema da formação de professores é central diante de uma política de construção e de consolidação de um pensamento conservador, como a que estamos vivendo.

Ao analisar o fenômeno nos EUA, Diniz-Pereira (2008) apresenta a disputa entre grupos neoliberais e neoconservadores na orientação da formação desses profissionais naquele país. A disputa pela formação dos professores tem se manifestado seja pela flexibilização do espaço formativo (próprio local de trabalho, nas instituições de Ensino Superior), seja na defesa de uma formação técnica e neutra desse profissional. Além disso, há uma estrutura de controle do trabalho do professor que cresce e se fortalece a partir dos vários exames em larga escala. Essa política de racionalização da formação e do trabalho docente contribui para a desqualificação dos professores devido à intensificação do trabalho e à perda de autonomia e respeito.

Junto a isso, o movimento Escola Sem Partido, que tem estimulado a censura e o policiamento das ações dos professores em sala de aula, contribui para o crescimento de atritos entre estudantes e educadores, entre o aprofundamento de uma relação de desconfiança e de hostilidade entre família e escola. Em um contexto em que a profissão tem sido pouco atrativa para jovens estudantes brasileiros, tememos que o clima atual contribua para maior resistência ainda à profissão.

\section{CONSIDERAÇÕES FINAIS}

Vale lembrar o alerta que faz Apple (2003) ao estudar o movimento de "modernização conservadora" nos EUA. Os movimentos direitistas reconheceram que para vencer no Estado é também preciso vencer na sociedade civil e, para tanto, estão em busca de realizar um projeto educacional que contribua para a consolidação da pauta econômica. 
Faz-se necessário reconhecer que alguns dos argumentos desses grupos são ouvidos exatamente porque estão conectados com aspectos da realidade vivida pelas pessoas, ou seja, que eles têm conseguido, de algum modo, articular-se a temas que ressoam profundamente em experiências, temores, esperanças e sonhos das pessoas em sua vida cotidiana.

Importa que retomemos nosso projeto e nossa atuação cotidiana na disputa por essa conexão, ou seja, pela referência aos ideais progressistas como aqueles que contribuirão para a superação das desigualdades e da violência social. Nessa luta, a escola e, em especial, o Ensino Médio são estratégicos e potentes para a contraposição a esse projeto cultural conservador. Portanto, a disputa por agendas econômicas do século XXI constróise com base em uma guerra que é fundamentalmente discursiva. É uma guerra pelo estabelecimento de novos discursos.

\section{REFERÊNCIAS BIBLIOGRÁFICAS}

APPLE, Michael. Educação à Direita: Mercados, Padrões, Deus e Desigualdade. SP: Cortez/Instituto Paulo Freire, 2003.

DINIZ-PEREIRA, Júlio. Formação Docente nos Estados Unidos: aliança conservadora e seus conflitos na atual reforma educacional norte-americana, in Educação \& Sociedade, v. 29, n. 102, jan/abr 2008.

ESTADO DE SÃO PAULO. Conselho Estadual de Educação. Deliberação n. 157 de 26 de dezembro de 2016.

LUZURIAGA, L. História da educação pública. Tradução e notas: Luiz Damasco Penna; J. B. Damasco Penna. 2. ed. São Paulo: Companhia Editora Nacional, 1959. (Atualidades Pedagógicas). v.71.

MINISTÉRIO DA EDUCAÇÃO. Conselho Nacional de Educação. Resolução n. 2 de $1^{\circ}$ de julho de 2015.

KRAWCZYK, N. e FERRETTI, C. Flexibilizar para quê? As meias verdades da reforma do ensino médio. Brasília: Retrato da escola, v.11, n 20.

SANTOS, Danielle e ZAN, Dirce. Ensino Médio e Educação Profissional: o marco das criações dos Institutos Federais de Educação, Ciência e Tecnologia, in SARTÓRIO, Lúcia; LINO, Lucília e SOUZA, Nádia (orgs.) Política Educacional e Dilemas do Ensino em Tempos de Crise: juventude, currículo, reformas do ensino e formação de professores. SP: Editora Livraria da Física, 2018. 